doi: $10.7213 /$ rebrae. 6070

ISSN 1983-8484

Licenciado sob uma Licença Creative Commons

\title{
O processo estratégico em médios negócios paulistanos: o percurso do plano à prática
}

\author{
The strategic process of SME in São Paulo: the plan's trajectory to the practice
}

Beatriz de Azevedo Blandy ${ }^{[a]}$, Belmiro do Nascimento João ${ }^{[b]}$

[a] Mestrado em Administração, Pontifícia Universidade Católica de São Paulo, PUC/SP, Brasil. Mestre em Administração pelo Programa de Estudos Pós-Graduados em Administração PUC/SP, e-mail: bia@pratica.etc.br

[b] Pós-Doutorado, Universidade de São Paulo, USP, Brasil. Professor Programa de Estudos Pós-Graduados em Administração PUC/SP, e-mail: belmirojoao@gmail.com

\section{Resumo}

Este é um estudo de cunho exploratório e qualitativo sobre o processo estratégico, segundo abordagem que entende a estratégia como uma prática. Essa abordagem recebe contribuições da filosofia e das ciências sociais, apropriando-se do conceito de prática social e aplicando-o aos estudos da gestão. Através da análise do discurso de nove entrevistas com estrategistas, executivo de médios negócios apresenta uma tipologia em estágios que agrega e esclarece aspectos do processo de fazer estratégia, do ponto de vista de seus praticantes. Nesse sentido, utiliza excertos da fala dos entrevistados, aproveitando-se dos principais temas por eles abordados, para evidenciar os aspectos constitutivos de cada estágio.

Palavras-chave: Estratégia como Prática. Processo Estratégico. Strategizing. Estrategistas. PME.

\begin{abstract}
This research is a qualitative and exploratory study about strategic process in an approach that understands the strategy as a practice. This approach receives contributions of philosophy and social sciences, appropriating the concept of social practice and applying it to studies of the management. Through discourse analysis of nine interviews with strategists, the sme executive has staged a typology that combines and clarifies aspects of the process of making strategy from the perspective of its practitioners. In this sense, uses excerpts from the speech of interviewees, taking advantage of the main themes addressed by them as evidence of the constituent aspects of each stage.
\end{abstract}

Keywords: Strategy as Practice. Strategic Process. Strategizing. Strategists. SME. 


\section{Introdução}

O objetivo deste artigo é contribuir para os estudos no campo da estratégia, através de avanços teóricos recentes no campo da prática e de uma pesquisa focada em aspectos dessa prática. Escolheu-se uma abordagem processual da criação e implementação de estratégias, cuja parte empírica será aplicada em médios negócios. Este é um segmento pouco explorado em estudos estratégicos, usualmente voltados para aspectos da performance de grandes empresas.

Tradicionalmente, os resultados estratégicos são relacionados ao desempenho das organizações, desprezando suas especificidades e as correlações com atividades, instrumentos e grau de envolvimento dos seus praticantes. Atualmente num contexto, de ambientes competitivos e instáveis, há algum consenso, de que é na prática e no processo que vai das intenções às realizações, nas quais efetivamente se auferem resultados. Ou seja, os aspectos diferenciais do desempenho das firmas estão cada vez mais depositados na competência de estrategistas e no percurso que vai do plano à prática. Por essa razão, intenciona-se pesquisar na prática e através de seus praticantes, aspectos deste processo estratégico e suas consequências para as organizações em que ele se dá.

A escolha por médios negócios permitiu que se unisse a função de estrategistas e gestores estratégicos. Considera-se que a percepção que esses gestores têm da sua própria prática, ao exercerem a função de estrategistas e também de responsáveis pela sua concretização, é uma oportunidade de mapear essa prática, seus percursos e resultados.

Focalizam-se a partir daí, aspectos da prática, tais como o quanto proposições estratégicas são intencionais e planejadas e se o processo de construção dessas propostas está explícito em atividades da organização. Busca-se compreender quem participa, os recursos de poder implicados, seus documentos e, finalmente, como esses aspectos impactam os resultados obtidos pelas empresas pesquisadas, segundo a percepção de seus principais estrategistas.

Essa pesquisa e a análise de seus resultados referenciam-se em uma abordagem em que a estratégia é vista como uma prática, realizadas por pessoas dentro de organizações. 0 conceito subsequente, de processo estratégico, é entendido como uma dinâmica que envolve estas pessoas, imaginando estratégias e concretizando-as em suas ações.
A partir dessas considerações sobre o campo, a opção pela prática e o delineamento de quem são os praticantes, pode-se formular a questão que norteia essa pesquisa: Na visão de seus empreendedores e principais estrategistas como se dá a prática e o percurso da estratégia em médios negócios na Grande São Paulo?

Neste artigo, retomam-se aspectos teóricos e metodológicos que situam a estratégia como uma prática. A partir de um modelo de análise, criado a partir do estudo de um corpus de dados, cuja fonte é o discurso dos estrategistas, define-se estágios da prática estratégica, que podem contribuir para a compreensão de como ele realmente se dá no contexto dos médios negócios. Finaliza-se com as conclusões que este estudo permitiu, dentro do seu caráter exploratório, original e incomum aos estudos do campo estratégico.

\section{Revisão teórica}

Em cenários instáveis, onde as variáveis que impactam resultados estratégicos são cada vez mais diversas, as pesquisas em estratégia têm sido dominadas por abordagens tipicamente econômicas, tanto para organizações, como os mercados em que atuam. É nesse campo e a partir de sua lógica e dinâmica, que se estuda como se delineiam diferentes estratégias, desenvolvem-se processos de planificação, tomadas de decisão ou mudanças. Sob este ponto de vista, estratégia é vista como algo próprio e de propriedade das organizações.

Nesse cenário, cresce a necessidade do reconhecimento de outros aspectos desse processo e do uso de uma lente para compreender como se dão e quais as razões de êxitos e fracassos. Assim, ao aproximar-se do que efetivamente acontece nas organizações e dos processos que levam a efetivos resultados, cresce a visão de que estratégia é uma prática, algo feito por pessoas dentro de organizações, em interações diversas. Mesmo que, enquanto resultado, possa ser considerado como uma propriedade dessas organizações.

A estratégia como prática propõe uma abordagem que empresta conceitos e instrumentos de teorias sociais e vem se constituindo em uma base sólida para aproximar a pesquisa nessa área de estudos de quem, como e porque se faz estratégia nas organizações. Essa abordagem híbrida e multidisciplinar abre um amplo espectro de possibilidades 
que leva, simultaneamente, a novas técnicas de pesquisa, como, por exemplo, a etnografia, a pesquisa-ação, a análise de discurso e a autoinvestigação (WHITTINGTON, 2004). Essas metodologias exigem, por sua vez, um olhar mais detalhista, exploratório, o envolvimento dos praticantes e um aparato metodológico plural. Além disso, abre-se aí uma agenda gerencial e formadora, aumentando significativamente a geração de conteúdos úteis à ação de gestores e seu desenvolvimento como estrategistas.

\section{As raízes da Estratégia como Prática}

Em Johnson et al. (2007), citam-se quatro amplas tradições teóricas como diretamente engajadas em aspectos da ação prática e suas atividades, exploradas pelo pragmatismo e por conceitos originários das teorias sociais. A primeira, conhecida como Situated Learning (Aprendizagem Situacional), aproxima-se de como as pessoas aprendem e reproduzem modelos e comportamentos nas suas atividades cotidianas. Essa didática da aprendizagem através da experiência direta mostra a importância das relações horizontais, da compreensão e o manejo de um "sistema de atividades" pelo qual flui um conhecimento dinâmico, depositado nos fazeres e seus protagonistas. Há outras importantes correntes teóricas que relacionam aprendizagem e atividades, como os estudos dos psicólogos russos Vigotski (1989) e Leontiev (1978). Vygotski (1989) ao cunhar o conceito de zona de desenvolvimento proximal, afirma que é neste terreno, entre o que se conhece e o desconhecido, onde potencialmente se desenvolve a aprendizagem. Um conceito importante sobre a aquisição de conhecimentos e atitudes, construído a partir da observação das intervenções sociais e do fazer em grupo.

A segunda, fortemente influenciada pela psicologia, admite os limites da racionalidade e a produção de uma subjetividade nas decisões e na ação humana. Destaca a singularidade de cada ator social e enfoca como se delineiam as rotinas organizacionais, a partir das atividades desses atores, interagindo na prática e coletivamente. Eixo em torno do quais se articulam conceitos como protagonismo, inovação e reiteração. Inspira conceitos chave como os complementares sensemaking and sengiving que unem a aprendizagem, a prática e a importância do discurso, presentes nas formulações estratégicas e nas narrativas da prática.
A terceira, chamada de Neoinstitucionalista, representa um avanço das teorias institucionais em função da teoria crítica e dos estudos de Foucault. A partir dessa evolução, pode-se admitir a existência de um campo institucional e situar melhor a gama de interesses que pautam as estratégias das organizações. Assim, além das rotinas e atividades, temos as normas e a cultura institucional, delineando como as organizações devem e querem ser. A existência de um campo onde se dá a estratégia, uma das grandes contribuições da teoria crítica, transformou a prática de administradores burocratas e autocentrados em atores estratégicos que internalizam as responsabilidades institucionais e os resultados de sua própria performance (KNIGHTS; MORGAN, 1991).

A quarta contribuição teórica é a Actor-Network Theory. Seus principais conceitos e conteúdos estão relacionados à interação ou atuação em rede de atores institucionais. Suas contribuições para este estudo estão no questionamento da divisão entre micro e macros níveis e a estreita relação entre conteúdo e processos Além disso, utilizaram-se métodos de pesquisa, que seguem a máxima metodológica de "seguir o ator" (LAW; CALLON, 1988), uma concentração intensiva na observação das pessoas e suas ações.

Ao voltar-se para a prática, a estratégia serve-se das proposições da filosofia pragmática e do conceito de prática das teorias sociais. Interesses comuns a essas disciplinas podem ser condensados em três itens: a extensão e natureza das intervenções dos envolvidos, o relacionamento entre microatividades e macroníveis de análise e a aproximação dos atores sociais e as capacidades e recursos com que atuam nas suas vidas reais e a forma como reproduzem e modificam regras e contextos sociais, de forma autoral e própria (JOHNSON et al., 2007).

\section{O Desenvolvimento da Estratégia como Prática}

0 artigo de maior impacto (ISI Web of Knowledge, 2011) no campo continua sendo o de Whittington (1996) que mapeia o desenvolvimento do pensamento estratégico desde a década de 60 e identifica uma perspectiva emergente em estratégia como prática. Esta perspectiva concentra-se em estrategistas e no strategizing ao invés de organizações e suas estratégias. A partir deste ponto de referência e de muitos outros, entre o final da década de 90 e primeira do atual século, observar-se a formação de uma 
abordagem, conhecida globalmente como Strategy as Practice ou S-a-P.

A S-a-P reúne uma produção acadêmica que explora temas diversos e proposições metodológicas (WHITTINGTON, 2006, 2004; JARZABKOWSKI, 2004; BALOGUN et al., 2003; VOLBERDA, 2004; CLEGG et al., 2004), situa sua relação com outras abordagens (JOHNSON et al., 2007), assim como explicita a relação entre um micro-olhar e macrocontextos (SAMRAFREDERICKS, 2003; EISENHARDT, 1989) e enfoques como a condução de mudanças (GIOIA; CHITTIPEDDI, 1991; BALOGUN; JOHNSON, 2004,2005), utilização de planos, tecnologias e instrumentos de análise (BARLEY, 1986; OAKES et al., 1998; KING, 2008) e dinâmicas de atuação (LANGLEY, 1986; BURGI et al., 2005; MACIEL, 2007).

Uma visão atual desta abordagem não poderia deixar de citar seus autores de maior impacto (ISI Web of Knowledge, 2011) tais como: Jarzabkowski, Seidl, Whittington, Balogun, Chia, Kaplan, Langley, Moisander e Rouleau. Sua produção escrita é quase totalmente em inglês e concentrada na Inglaterra, Canadá, Suécia e Finlândia, embora esteja paulatinamente se espalhando por outros núcleos acadêmicos pelo mundo. A gênese e expansão dessa abordagem vêm sendo capitaneada pela Universidade de Aston (Reino Unido) da qual faz parte Paula Jarzabkowski que tem um grupo de pesquisa em economia e estratégia (Economics \& Strategy Group). Em seguida tem-se a HEC Montréal (Canadá), na qual Ann Langley tem um grupo de pesquisa, e pelas Universidades de Bath e Warwick. Há uma rede internacional de pesquisa (Strategy as Practice International Network) cujos membros institucionais são formados por oito instituições: Universidade de Zurich (Suíça), Hanken School of Economics (Finlândia), HEC Montréal (Canadá), Aston University (Reino Unido), Lancaster University (Reino Unido), Universidade de St Gallen (Suíça), Universidade de Oxford (Reino Unido) e Universidade de Sydney Business School (Austrália).

Nesse contexto e a partir de uma rede de pesquisadores que anima discussões, trocas de informações, canais de publicações e eventos, tem-se também uma produção acadêmica que levanta, avalia e discute os avanços da própria abordagem prática em estratégia. Citam-se aqui dois exemplos que podem dar uma ideia do momento atual e dos caminhos a serem trilhados.

Jarzabkowski e Spee (2009) mapeiam e avaliam criticamente o crescente corpo de pesquisa da estratégia como prática. Após uma introdução sobre o surgimento e fundamentos, estruturam três eixos principais, com base em terminologias, questões e agenda de pesquisa. Primeiramente, analisam conceitos tais como praticantes e praxis e arrolam uma tipologia dos nove domínios possíveis, com base na maneira que diferentes estudos conceituam o praticante da estratégia e o nível de práxis estratégica que objetivam explicar. Em segundo lugar, retomam o conceito de prática, amplamente adotado, mas segundo os autores, de forma ainda inconsistente na literatura S-a-P. Mapeiam os vários conceitos de práticas que informam o campo e apontam avenidas para pesquisas futuras. Ao final há um chamado à pesquisa para desenvolver e fundamentar resultados que podem melhor explicar ou informar a praxis da estratégia. Cinco categorias de resultados são encontradas dentro de estudos empíricos e o artigo conclui com um resumo do estado atual do campo e recomendações.

Vaara e Whittington (2012) também uma revisão recente, mostrando como a S-a-P vem promovendo o avanço das teorias sociais nos temas da gestão estratégica, oferecendo alternativas à análise de performances, ampliando o escopo dos estudos organizacionais e promovendo novas abordagens metodológicas. E, no sentido de levar a sério a perspectiva prática, apontam algumas direções a serem desenvolvidas como o poder de agência de uma rede de práticas, o reconhecimento de aspectos macroinstitucionais desta rede, aspectos emergenciais do fazer estratégico, impacto dos materiais utilizados nesse fazer e a importância de uma análise a crítica em relação à própria S-a-P.

Complementam essa síntese, lembrando como o conceito de prática instrumenta os estudos de gestão a compreenderem e relacionarem o trabalho estratégico (strategizing), o processo e os resultados estratégicos. Ao oferecem alternativas a modelos individualistas de tomada de decisões, permitem aos pesquisadores identificar atores, que criam estratégias e tomam decisões, numa rede de práticas e atividades organizacionais. Uma visão que estende o conceito de performance e contribui para temas tais como as distinções entre estratégias deliberadas e emergentes, as fronteiras que definem atos de formular a estratégia e implementá-la e níveis de intencionalidade e consciência implicados nessa dinâmica.

Assim, por sua configuração multifacetada, plural e multidisciplinar considerou-se a Estratégia como 
Prática uma plataforma segura para guiar essa investigação sobre a prática e o processo estratégica em médios negócios.

\section{Metodologia de pesquisa e modelo de análise}

No artigo que se propõe a dar três respostas aos desafios metodológicos que enfrentam os pesquisadores que pretendem estudar o fazer estratégico, Balogun e Johnson (2005) retomam o conflito entre aproximar-se dos detalhes e contexto do fenômeno estudado a ao mesmo tempo ampliar o escopo escolhido e atender às varias partes da organização. Ou seja, sabe-se, de saída, que há que se enfrentar a incompletude de escolhas metodológicas que não contemplarão igualmente as exigências de uma visão que explore aspectos sequenciais do processo estratégico e ainda comprovem sua frequência, constância ou ainda contemplem outros pontos de vista dentro das organizações pesquisadas.

Escolhas metodológicas passam obrigatoriamente por uma unidade de análise, a natureza e o tamanho da amostra a ser pesquisada. Neste caso, a unidade analisada é a prática do processo estratégico, entendida como a uma sequência de eventos ou atividades e seus resultados (JOHNSON et al. 2007). Esta escolha se justifica pelos conceitos fundamentais da abordagem prática, em que a estratégia não é feita só por diretores ou proprietários, mas se espalha pelo tecido organizacional e transborda ainda para stakeholders e produtores de sentido para ações estratégicas. Esta visão processual reconhece uma dinâmica, coordenadas de tempo e espaço mutáveis e pontos de vista singulares, favorecendo a escolha de métodos quantitativos e interpretativos, como a análise de conteúdo e de discurso (BARDIN, 2009).

Além disso, ao considerar como atividade estratégica, toda atividade que contribui para a orientação geral do negócio, há que se identificar esta específica sucessão de atividades e seus envolvidos. Apoiados em teorias sociais, Hendry e Seidl (2003) definem atividades estratégicas como episódios demarcados, por uma situação de exceção em relação aos padrões rotineiros e operacionais da organização, de forma a permitir um pensamento e um discurso reflexivo sobre as rotinas e direções, com o potencial de alterar uma trajetória estratégica.

Essa sequência de atividades, conteúdos e atuações de todos os envolvidos nessa cadeia, que vai dos planos à prática, da intenção à realidade é o que está contemplado pelo conceito de processo estratégico. 0 aspecto central a ser destacado é o seu caráter móvel, episódico e sequencial no qual participantes e seu desempenho vão afetando e sendo afetados sucessivamente por uma série progressiva de atividades e seus conteúdos.

Esta escolha apoia-se em uma evolução da perspectiva funcionalista, que já não confia que os atores envolvidos são unicamente movidos pela racionalidade, pela competitividade e lucratividade. Daí a importância em auscultar seus percalços, desafios e soluções. Atualmente os conteúdos simbólicos que formam uma cultura organizacional e as competências pessoais dos envolvidos são considerados recursos relevantes para o sucesso de uma estratégia. Assim, interpretar as razões e categorizar a forma como operam os principais estrategistas de um número restrito de organizações pode-se constituir em uma via segura para estudar o fazer estratégico.

Ao constituir uma amostra de conveniência de nove empresas de médio porte (Figura 1), o principal critério foi manter um tamanho reduzido de organizações pesquisadas, com uma grande diversidade de setores e negócios. Nesta amostra, levantaram-se os diferentes processos estratégicos, num modelo de estudo de casos múltiplos (YIN, 2010). Através de entrevistas, guiadas por um roteiro comum, mapearam-se investimentos em planejamento estratégico, intenções ou formulações projetivas, atividades estratégicas e seus participantes.

A veracidade e a clareza dos testemunhos foram garantidas pela técnica de "seguir o ator" (LAW; CALLON, 1988). Essa máxima implica respeitar o raciocínio e a narrativa dos estrategistas (Figura 2), conduzindo a conversa de forma a aprofundar o roteiro, no qual se contemplava a descrição do processo estratégico e seus conteúdos; características do ambiente e setor em que a empresa se insere e aspectos subjetivos descritos pelo estrategista na narração da sua experiência.

$\mathrm{Na}$ análise do conteúdo desses discursos (BARDIN, 2009), as transcrições das entrevistas foram separadas em pequenos blocos, identificados por assuntos e posteriormente estes trechos foram agrupados em quatro blocos temáticos, presentes no roteiro: conteúdos estratégicos; o processo estratégico; impactos do ambiente; aspectos subjetivos do estrategista (formação, insights e planos futuros). A análise comparativa desse corpus concentrou-se nos 


\begin{tabular}{|c|c|c|c|c|}
\hline Código & Principais atividades & Setor em que atua & Trabalhadores & Atividade \\
\hline $\mathrm{F} 1$ & $\begin{array}{l}\text { Desenvolvimento, produção e } \\
\text { comercialização de produtos farmacêuticos }\end{array}$ & Farmacêutico & $\begin{array}{c}150 \\
\text { (na matriz) }\end{array}$ & 52 anos \\
\hline $\mathrm{F} 2$ & $\begin{array}{l}\text { Desenvolvimento, produção e } \\
\text { comercialização de produtos para cabelo }\end{array}$ & Cosmético & 280 & 75 anos \\
\hline F3 & $\begin{array}{l}\text { Planejamento, produção e } \\
\text { suporte de ambientes digitais }\end{array}$ & Comunicação Digital & 62 & 5 anos \\
\hline $\mathrm{F} 4$ & $\begin{array}{l}\text { Desenvolvimento, comercialização e } \\
\text { distribuição de produtos de limpeza }\end{array}$ & $\begin{array}{l}\text { Higiene e limpeza } \\
\text { profissional }\end{array}$ & 65 & 34 anos \\
\hline F5 & Lavanderia e tinturaria industrial & Têxtil & 315 & 21 anos \\
\hline F6 & Design, Arquitetura e Comunicação & Branding e Design Estratégico & 20 & 30 anos \\
\hline F7 & $\begin{array}{l}\text { Comercialização e importação de } \\
\text { acessórios musicais }\end{array}$ & Instrumentos Musicais & 56 & 15 anos \\
\hline F8 & Consultoria e estratégica de marketing & Comunicação e Marketing & 34 & 4 anos \\
\hline F9 & $\begin{array}{l}\text { Comercialização e importação de } \\
\text { máquinas para construção civil }\end{array}$ & $\begin{array}{l}\text { Atacadista de } \\
\text { máquinas }\end{array}$ & 4 & $\begin{array}{l}2 \text { anos } \\
\text { (no Brasil) }\end{array}$ \\
\hline
\end{tabular}

Figura 1 - Caracterização e codificação das empresas componentes da amostra Fonte: dados da pesquisa.

\begin{tabular}{c|c|l|l}
\hline Código & Idade & Formação & Cargo que ocupa \\
\hline E1 & 55 & Administração de Empresas & Diretor de Marketing \\
\hline E2 & 52 & Artes Plásticas & Diretor Industrial \\
\hline E3 & 38 & Jornalismo & Diretor de Novos Negócios \\
\hline E4 & 51 & Engenharia Metalúrgica & Diretor Geral \\
\hline E5 & 50 & Química Industrial & Sócio-Diretor \\
\hline E6 & 57 & Bacharelado em Letras Modernas & Sócio-Diretor \\
\hline E7 & 58 & Fotografia e Música & Sócio-Fundador \\
\hline E8 & 42 & Economia e Sociologia (MBA) & Sócio Administrador \\
\hline E9 & 59 & Arquitetura &
\end{tabular}

Figura 2 - Caracterização e codificação dos entrevistados Fonte: dados da pesquisa.

nove textos sobre o processo estratégico, que apontavam práticas comuns ou diferentes e, muitas vezes, se aproximavam muito, mesmo em negócios de setores muito diferentes.

\section{Em busca de um modelo de análise}

Ao mapear o percurso de atividades estratégicas, quem participa delas e sua relação com alguns resultados percebidos pelos entrevistados, retoma-se a pergunta inicial deste estudo. Ao aprofundar-se no processo estratégico das nove empresas pesquisadas, vislumbrou-se um agrupamento em três estados (Figura 3) relacionados às características essenciais destes percursos e os significados atribuídos a este conjunto de atividades, na percepção dos entrevistados. A palavra estágio, escolhida para definir os agrupamentos de percursos estratégicos, pode significar momento ou período específico de um processo e também as etapas sucessivas na realização de algo. Desde já, afirma-se que o primeiro significado é o empregado e mais adequado para conceituar o que há em comum ou distinguir o momento em que se encontram os processos relatados. Deve-se esclarecer a inexistência de intenção evolutiva, mesmo que ela possa existir nas firmas e que algumas tradições teóricas a tenham como premissa.

Volberda (2004), numa perspectiva atual de estratégia, reconhece que etapas bem definidas de 
processos estruturados, em estruturação e intuitivos.

planejamento e recursos dirigidos podem não ser suficientes para dar conta dos desafios dos tempos que vivemos. Ao mesmo tempo, a narrativa dos estrategistas expõe ou ainda revela o desejo de criar modelos e formas de atuar que provenha sentido para os integrantes e stakeholders, de forma a melhorar a adaptação ao ambiente e resultados alcançados pelas empresas.

Maitlis e Lawrence (2003) e Gioia e Chittipeddi (1991) relatam processos similares ao pesquisar padrões de desempenho ou relacionados a mudanças e conquistas estratégicas em organizações. Nesses casos, a experiência vivida e a condensação de todas as fontes textuais ou não, fizeram emergir modelos de análise. Estes modelos geraram padrões e estágios que deram forma e suporte à análise de dados, como no presente estudo. Outros autores também podem ser incluídos nessa via, (OAKES et al. , 1998, DOUGHERTY et al., 2004, MANTERE, 2005, SAMRAFREDERICKS, 2003) onde a proximidade e familiaridade com praticantes e dados gera modelos de análise que fazem esse trânsito entre a observação, escuta e registros detalhados e uma análise mais ampla do tema estudado, recorrendo a tipologias e padrões esclarecedores.

Ao utilizar um modelo de análise dessa natureza, o propósito é estabelecer comparações entre os percursos pesquisados e os conceitos aqui apresentados. 0 agrupamento emergiu de assuntos recorrentes ou pontos de vista muito diferentes dos entrevistados e as evidências utilizadas para justificá-los foram retiradas do seu próprio discurso, conservando sua riqueza coloquial e relatos da experiência vivida.

Para melhor caracterizar esses estágios, utilizaram-se três dimensões-chave, que integram conteúdos encontrados e referenciais teóricas. A primeira é constitutiva, ou seja, analisam-se aspectos comuns a
A segunda pressupõe a existência de uma dinâmica e focaliza os forças e limites de cada estágio. A terceira identifica aspectos muito característicos a cada estágio, que podem ser considerados uma tendência evolutiva ou um item importante para sua manutenção.

\section{Estágios do processo estratégico}

No estudo das práticas, como o processo estratégico, revela-se o quanto os estrategistas são responsáveis pela sua perpetuação, mudanças ou extinção. A Teoria da Estruturação apresenta o conceito de rotinização para explicar as práticas das ações humanas. Para Giddens (1984, p. XXV) "A rotina (tudo que é feito habitualmente) constitui um elemento básico da atividade social cotidiana (...). A rotinização é vital para os mecanismos psicológicos por meio dos quais um senso de confiança ou segurança ontológica é sustentado nas atividades cotidianas da vida social". Esse autor destaca como e por que as atividades, considerados como o fio condutor da interação social, se transformam em rotinas. A rotinização ou estruturação dessas atividades vincula o caráter fugaz de eventos solitários à reprodução social e à "fixidez" aparente das instituições.

A eleição dos três estágios segue uma escala de constituição e estruturação de um processo que suporte formulações, implementações e resultados estratégicos nas empresas pesquisadas. 0 agrupamento foi definido por aspectos relacionados aos discursos, tais como abordagem dos temas, repetição e equivalência de assuntos. Os significados atribuídos ao processo estratégico que relatam é o que une os integrantes de cada grupo e os diferencia dos classificados em outros estágios.

\begin{tabular}{|c|c|c|c|c|}
\hline \multirow{8}{*}{ 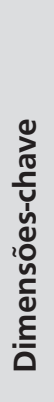 } & \multicolumn{4}{|c|}{ Estágios } \\
\hline & & Estruturado & Em Estruturação & Intuitivo \\
\hline & Empresas & $F 1, F 2, F 4, F 8$ & F3, F7, F9 & F5, F6 \\
\hline & Entrevistados & $\mathrm{E} 1, \mathrm{E} 2, \mathrm{E} 4, \mathrm{E} 8$ & E3, E7, E9 & E5, E6 \\
\hline & Aspectos essenciais & Esforços e ganhos da Estruturação & Aonde queremos chegar & O valor da intuição \\
\hline & \multirow{2}{*}{ Forças e limites } & A burocratização & As equipes, o motor do processo & Inovação constante \\
\hline & & A participação & O ritmo da mudança & Impactos do ambiente \\
\hline & Características chave & O gestor de gestores & O papel da tecnologia & O estrategista como líder \\
\hline
\end{tabular}

Figura 3 - Configuração de agrupamento de empresas, em relação ao processo estratégico Fonte: dados da pesquisa. 
Escolheram-se excertos do discurso de cada entrevistado para demonstrar estas características e relacioná-las às contribuições teóricas da abordagem prática e de outros estudiosos interessados em como estratégias são formuladas e implementadas.

\section{Os processos estruturados}

Segundo a visão adotada, não há um ponto ótimo de estruturação; assim pode-se assumir apenas que quatro deles são significativamente mais estruturados que os demais. Os entrevistados aludem aos esforços necessários para estruturar e manter processos de constituir e colocar em prática conteúdos estratégicos. Dizem o quanto isso é custoso, que há muito a fazer e como a repetição de fórmulas bem sucedidas pode levar à burocratização ou mediocridade de resultados.

Em função das entrevistas, sabe-se que o planejamento estratégico é marcante neste processo. Mesmo assim, este evento está presente em quase todas as empresas do grupo há, em média, cinco anos. Dado que mostra que os esforços de planejamento e seu impacto em decisões e ações cotidianas são eventos recentes. 0 entrevistado E4 descreve o estágio inicial de um planejamento estratégico anual e seu potencial de ampliar e atualizar planejamentos anteriores.

Trata-se de uma prática, (...) No ambiente externo, sumarizamos o cenário macroeconômico e o cenário do mercado. É uma parte que tem campo pra inovação, onde as pessoas jogam tendências, ideias, conversas de para onde as coisas estão caminhando.

Esta prática, como diz E4, é repetida anualmente na empresa, estruturada com método, nomenclatura própria e uma intensa participação dos diretores e gerentes. Já na empresa F8, uma avaliação ocupa esse espaço do momento anual de planejar, ao construir sentidos e alinhamento interno, mostrando que há outras possibilidades de estruturar-se um processo de fazer estratégia.

Somos mais de fazer do que parar para pensar aquilo que a gente quer. Criamos um processo de avaliação, que se baseia em dados qualitativos e quantitativos (...) assim as pessoas aqui estão muito empurradas pra fazer duas coisas. Uma é procurar projetos, outra é propor metodologias. Isso tem um valor e vira bonificação.
Segundo Schatzki (2001), práticas internalizadas em um campo organizacional, geram sentidos compartilhados e reiterados por seus praticantes. Essa concepção da prática apoia uma concepção processual de estratégia. Verificou-se que em todos os casos, além do planejamento estratégico ou anual, outros episódios estratégicos e rotinas são igualmente importantes. Podem ser considerados tanto como recurso, como instrumento de controle. Informam e formam o fazer de quem está envolvido e também tem o poder de enquadrar seus participantes dentro de uma lógica institucional (WHITTINGTON, 2006). 0 trecho do discurso do entrevistado E2 evidencia essa dupla função:

Nessa reunião dos seis (três diretores e três gerentes), normalmente duas vezes por semana às sete da manhã. É terrível. É meio uma chamada oral mesmo. A gente passa isso pra tela, cada um apresenta a sua. 0 que fez e o que não fez.

Os ganhos associados aos desafios da gestão são perceptíveis e essenciais à manutenção de processos estruturados. Uma memória cumulativa das metas e resultados alcançados e a capacidade de aprendizagem com próprio processo são os ganhos apontados pelo entrevistado E2:

Nós somos conservadores no nosso planejamento estratégico. Nos últimos 5 anos, tudo o que a gente projetou, ultrapassou. Precisa estar cada vez mais bem planejado pra não tomar surpresas das faltas de coisas. (...) Você não pode crescer mais porque você não vai cumprir.

O alinhamento estratégico foi uma das conquistas do entrevistado E1, que faz dez anos que acredita que deve haver uma área estratégica na empresa. Conseguiu no ano passado.

O problema é que não havia um pensamento estratégico no resto da empresa. Não havia alinhamento estratégico. De repente eu era surpreendido com um projeto de produto, gastado uma fortuna para uma área em que a gente nem pensava em atuar.

Já o entrevistado E4, retoma como o investimento em planejamento e gestão resultou no envolvimento e produtividade das equipes e como isso transparece nos resultados. 
Pra você ter uma ideia, na média, a gente dobrou em cinco anos e o número de funcionários é praticamente o mesmo. A gente tem muito orgulho e muita alegria dessa transformação desses últimos anos, estamos na vanguarda desse processo.

Numa classificação por estágios que propõe uma dinâmica ou uma evolução, verifica-se que os processos estratégicos relatados estão sujeitos a forças impulsionadoras e fatores limitantes. Pela sua relevância e adequação, os assuntos escolhidos nesse estágio são as questões relacionadas à participação (força) e a burocratização (limites).

Os relatos são pródigos em relação a quem e como participa do processo estratégico e as dúvidas e conflitos que este tema suscita, demonstrando que não há um ponto ótimo de participação. E que em toda política de participação, há uma expectativa do papel a ser desempenhado por cada segmento envolvido e o poder decisório atribuído a essa participação.

0 que se pode observar é que o nível de estruturação e reiteração dos processos estratégicos nas organizações permite uma explicitação mais clara de quem deve participar das projeções do que poderá acontecer nos próximos anos e participações mais duradouras e estáveis. 0 entrevistado E4 narra as conquistas deste último ano, quando conseguiram vencer algumas barreiras importantes de linguagem, ao criar uma dinâmica para disseminar estratégias anuais.

É feita pra todos, sem exceção. Desmembramos diretrizes em forma de oficinas. Todos são coparticipantes na oficina de montar e entender essa relação de causa e efeito da estratégia. Selecionamos casos da empresa e o pessoal conseguiu chegar um passo além ao fazer essa conexão entre estratégia e como acontece no dia a dia.

A prática também aponta limites da estruturação. A repetição anual e mecânica dos mesmos procedimentos passa a determinar resultados pobres e sem o potencial de transformação e atualização que estas atividades estratégicas devem ter. 0 mesmo entrevistado E4 conta o que pode acontecer em qualquer empresa.

A burocratização existe quando a agenda é cumprida sem paixão, sem inovação. 0 risco de burocratizar é começar a dar certo e você repete, acha que é uma formula. Aí você tomba, porque não é assim. Foi preciso resgatar essências, menos coisas e mais profundas. Fizemos mudanças importantes para ser mais efetivos.

Uma das características reveladoras do que constitui processos estratégicos estruturados é a presença em todos os relatos deste estágio de gestores do processo estratégico ou gestores de projetos gerados nessa cadeia de atividades. Esse fato não causa surpresa neste estágio, pois aqui esses processos são assumidos pelas empresas como essenciais para sua prática. Ainda assim é um novo recurso, com diferenças e peculiaridades, mas efetivamente presente nos quatro relatos, podendo ser considerada uma experiência relacionada à estruturação. Apesar das diferenças encontradas em cada empresa, foram citados como diferenciais para que se mantivesse uma proximidade entre os planos e a prática. Justificam-se pelo caráter precário desse processo e absolutamente dependente das pessoas que os faz existir. 0 entrevistado E1 relata:

Nós temos dois gestores aqui. 0 gestor de metas fica acompanhando as metas. Cada um tem sua, todas monitoradas num software. Ficou vermelhinho, o cara tem de vir e explicar o que vai fazer. Nós temos também o gestor de projetos. Uma é gestão do dia a dia, outra de projetos.

Já o processo assumidamente estruturado, criado e coordenado pelo entrevistado E4 tem um gestor que assume essa função dentro de uma organização em matriz, onde gerentes exercem outras funções além do seu cargo. Nesse caso é onde foi utilizada a denominação de gestor de gestores, que dá nome a esta dimensão dos projetos estruturados.

Tem um gestor que é o gestor dos gestores. A gente montou um processo que é o escritório de processos, chama Management Office. Essa pessoa é responsável por checar os indicadores, dar uma geral nos processos. Mas quem informa, quem traz é o próprio gestor.

\section{Os processos estratégicos em estruturação}

Segundo a teoria ator-rede, um processo está sempre in progress e esta característica pode ser mais ou 
menos aguda, no caso de uma cadeia de episódios estratégicos. Pettigrew (1977) afirma que estratégia pode ser entendida como um fluxo de eventos, valores e ações inseridos em um contexto. E Volberda (2004), alude à Escola das Configurações, na sua perspectiva dinâmica (MINTZBERG, 1973, 1978) (MINTZBERG et al., 2000). Nesta interpretação desta escola, as configurações possuem momentum (em que são alteradas) e inércia (quando tendem a ser mantidas). Reconhece-se que a maior parte das mudanças ocorre dentro de uma configuração e não entre elas.

Estar em transformação é um estado comum a todos os processos estudados, assim o que caracteriza este grupo é como seus estrategistas narraram o processo estratégico e seu momentum. Os três entrevistados (E3, E7, E9) afirmam que estão em estruturação, contam como a operam e, em diferentes intensidades, tem noções de onde querem chegar. A insatisfação com estruturas, rotinas ou a sua falta, pontua seus discursos, permeados por visões de como deveria ser ou será.

O entrevistado E7, diretor de uma empresa que importa e comercializa acessórios musicais, diz que está mudando tudo e exemplifica: "tive que mandar embora, depois de dez anos, dois gerentes comerciais, pessoas que criavam problemas que não faziam mais sentido". E conta como era e aonde quer chegar. "O planejamento estava sempre ligado a uma meta de vendas anual. Nos últimos cinco anos, invalidou ou envelheceu muito rapidamente a estrutura anterior [...] São vícios de uma empresa pequena, o nosso desafio hoje é se tornar uma empresa sem esses ranços.

Processos acelerados de crescimento, impactos do ambiente global e a necessidade de entregar o que foi prometido, mobilizam esforços centrados no imediato ou em problemas específicos. 0 entrevistado E3, relata eventos periódicos que podem conter conteúdos estratégicos, dizendo que semanalmente fazem uma "reunião da chapa". Nela analisam tudo o que está "quente na casa", trocando informações e tudo o mais. Em outro trecho, fala sobre planejamento:

A gente não tem um planejamento estruturado. Já me esforcei pra fazer... Aí começavam a entrar trabalhos e seis meses depois ia revisar, não se encaixava mais. As coisas acabam mudando. A gente vai elegendo algumas prioridades e tentando focar nelas. E conforme o tempo passa, olhamos o cenário e vemos onde está precisando trabalhar mais.
Todos os discursos evidenciam como a relação com gerentes e integrantes das equipes de trabalho são uma das forças motrizes para estruturar processos que atraiam, incluam, retenham e principalmente apontem diretrizes estratégicas da empresa para todos os colaboradores. No caso deste estudo, embasado em uma visão voltada para as atividades estratégicas e quem as realiza, esse tema explicita e confirma a atualidade dessa abordagem. 0 entrevistado E3 relata o esforço de sistematizar conteúdos estratégicos, para atrelá-los a formas de remuneração.

Dirigi umas rodadas de discussão com os sócios, agora estou descendo com os gestores, vendo o que acham e se não está faltando nada. Ali você tem os processos e as responsabilidades para serem discutidos com cada gestor, porque vou atrelar a remuneração variável aos processos da área.

O tempo é um dos fatores críticos para que atividades, seus protagonistas e sentidos, encontrem seu lugar na prática e cumpram os objetivos para os quais foram pensadas. Esse andamento escapa do controle dos estrategistas, premidos pelo ambiente ou suas expectativas futuras. 0 entrevistado E9, narra o desafio de se fazer entender por sócios que estão vivendo em tempos diferentes do intenso processo de crescimento da empresa, dizendo que há dois grandes problemas: "eles nunca entenderam e eu tenho minhas dúvidas se eles algum dia vão entender, a velocidade das coisas no Brasil" e complementa, "eles não conseguem entender a complexidade das coisas aqui".

Nesse processo, o estrategista não é o único tomador de decisões, mas um negociador e coordenador de processos. 0 entrevistado E7, admite sua condição de aprendiz.

Na verdade nós somos aprendizes nisso ainda. Precisamos gerar ferramentas de trabalho. Tem ter uma disciplina quase que tibetana. A gente sempre fala das reuniões. Reunião se é quinta-feira, é quinta-feira. 0 resto, transfere-se.

Nos três relatos de processos em estruturação, cita-se a enorme relevância que as Tecnologias de Inteligência desempenham nessa evolução. Esta questão também está presente em outros relatos, reconhecendo o valor de atores não humanos no desenvolvimento de estratégias, mas é neste grupo que ela aparece como um fator de estruturação. 0 
entrevistado E3, trabalha com comunicação digital e usa uma ferramenta que é o próprio ambiente de planejamento. Ele relata que é uma forma de você estruturar o planejamento e fazer o controle da casa, "vejo todos os jobs em tempo real, alimentado por várias pessoas, cada um contribuindo da sua mesa". E observa: "(...) Se eu tivesse de fechar um relatório semanal de 40 páginas, para cada um entender o que está rolando...Um ambiente e uma cultura que E7 esforça-se por implantar e consolidar num ERP.

Esse ano, o advento do ERP exige fazer calendários de reuniões. Nesta semana estamos trabalhando em um calendário de reuniões para os departamentos, as gerências.

\section{Os processos estratégicos intuitivos}

A tradição cartesiana aconselha a separar o problema da sua percepção, para ordenar o que está em jogo. Sem negar os benefícios desse distanciamento, uma visão processual busca o encontro entre estratégia, organização e indivíduo, questionando uma separação real entre um longo período de pensamento - a formulação de estratégias- seguido por um período de ação - a implementação de estratégias. A abordagem prática valoriza a combinação que possibilita pensar e agir estrategicamente, ou strategizing, termo que descreve como estrategistas agem e como estratégias emergem da prática. Para Wilson e Jarzabkowski (2004) fazer estratégia é uma combinação entre ação (animação) e direção (orientação), onde estrategistas são capazes de atuar, aproveitando contextos para transformar ou desafiar as práticas existentes.

Pode-se dizer que todo estrategista é também movido por intuições. Por isso, a classificação de alguns processos como intuitivos, teve como critério o discurso dos estrategistas E5 e E6, que se dizem assumidamente intuitivos. 0 entrevistado E5, dirige uma lavanderia industrial e descreve como age e pensa estrategicamente.

Sabe a estratégia que eu tenho no meu coração? Eu não deixo passar a menor oportunidade. Seja qual for. Eu grudo nela porque não sei se é boa ou ruim. Então vamos chamar isso de estratégia? Eu não deixo passar nenhuma chance. Chega uma coisa pra mim, vou fuçar pra ver se é interessante. Essa é a minha maior estratégia.
Já o entrevistado E6, que dirige um escritório de branding e design, formula a sua versão de estratégia, onde os movimentos de animação e orientação aparecem realçados, dizendo "A estratégia é um cenário onde você quer que as coisas aconteçam de um certo jeito e trabalha pra que isso se realize". E, localiza-se nesse cenário: "O meu papel é como é que eu mobilizo gente, primeiro para acreditarem que essa coisa pode acontecer e convencê-los (...) qual é a atuação que eu acho que eles têm de ter pra que a empresa flua nessa direção. Eu aprendo muito mais nesse processo do que ensino".

Nos dois relatos, observa-se que os processos estratégicos intuitivos concentram-se na atuação do estrategista. Segundo o mesmo entrevistado E6, essa capacidade de liderar equipes é um dos seus pontos fortes.

Acho que eu sou um bom líder. Consigo arrancar um brilho do olho e vontade de fazer. Embora seja a nível operacional, acho que também é estratégico. Para um projeto , qualquer que ele seja, é um dado decisivo.

Nas duas empresas, dá-se pouca importância ao planejamento. 0 entrevistado E6 conta ainda com essa ausência de planejamento, representou um vácuo e um descolamento da realidade.

Eu chegava a fazer o planejamento do ano. Passava batido. Então ficou essa coisa olímpica, essa incapacidade de refletir sobre a empresa. Isso acabou contaminando a equipe que acabou vendo que a direção não estava dirigindo. A direção não pode sonhar. 0 negócio descolou completamente da realidade.

Pode-se observar em todos os relatos, que a maioria dos setores passam por grandes transformações, uma característica comum a cenários globalizados e instáveis como os que se convive contemporaneamente. Aqui é impossível estabelecer comparações, mas pode-se dizer que o impacto dessas mudanças está muito presente nestes relatos. 0 entrevistado E5 narra como lida com um ambiente sensível à concorrência chinesa.

No ano passado tingimos duzentas toneladas de meia preta feminina. Faz três anos, que essa indústria têxtil gigante brasileira manda para nós. (...) Este ano compraram uns contêineres enormes de meias. Os caras trouxeram da China. 
A empresa F6 tem 30 anos de atuação e E6 relata o que aconteceu nesse setor.

Da visão artística passou-se para o desenho como um projeto. As faculdades de arquitetura ajudaram a passar essa visão. Depois foi o marketing, voltado para resultado. Até que finalmente, a onda atual, o design está ligado ao significado. 0 design ideal, é um planejamento, um conjunto de instruções para a indústria. Seja ele impresso, ou objeto.

Ao apontar aspectos favorecidos pela intuição, é notória a capacidade de inovar constantemente e buscar saídas para os desafios a serem vencidos pela empresa. 0 que chama atenção é a rapidez com que isso acontece e a liderança exercida pelos estrategistas entrevistados nesse sentido. Para E5 a inovação é uma vantagem competitiva e narra como gera valor para a empresa.

Aí é onde a gente ganha dinheiro [...]Todo nosso show room é renovado duas, três vezes por ano com as lavagens lá da Itália. A gente faz em média 5.000 amostras por mês, de lavagem, de tingimento. Tem umas 20 pessoas nesse setor. Aí que a gente vende nosso serviço.

O entrevistado E6 projeta uma nova fase para a empresa e conta qual é sua estratégia. Por este excerto, pode-se verificar que os aspectos constitutivos do estágio intuitivo permanecem, mesmo que sob uma reestruturação. Um movimento que pode ou não, levar a uma significativa transformação.

Estou apostando nessa rapaziada e na capacidade da gente se entusiasmar por vias novas. Acho que o não convencional acaba sendo uma visão estratégica.

\section{Conclusões}

Da escolha do tema aos procedimentos metodológicos, foi impossível escapar do dilema entre um campo quase infinito e uma amostra reduzida. Manter a diversidade das firmas e concentrar-se no discurso dos principais estrategistas de cada empresa e mostrou-se um recurso viável para gerar uma tipologia de como se faz estratégia em médios negócios. Os referenciais teóricos e metodologias de análise de discurso é que tornaram possível identificar padrões e considerá-los como estágios ou estados de do processo estratégico.

Apesar dos contínuos esforços dos estrategistas que relatam processos mais estruturados, do anseio que alguns entrevistados do estágio " em estruturação" dizem ter em relação à maior estabilidade, há que se resistir a qualificar uma tendência evolutiva entre eles. Acredita-se apenas que essas categorias de análise apuram o olhar do pesquisador para a prática e tem potencial para embasar novas investigações, que podem levar a conclusões mais robustas. Como poderia se esperar de um estudo exploratório termina-se exatamente no ponto onde uma etapa de aprofundamento em aspectos mais específicos deveria começar. Muitas direções se apresentam e ainda devem ser amadurecidas.

Quanto aos conteúdos percebidos na definição e estudo das características de cada estágio, dois aspectos chamam muita atenção, tanto pela intensidade com que aparece, quanto pelo seu potencial transformador. 0 primeiro refere-se à estruturação do próprio processo estratégico, que adquire relevância e efetividade nas organizações pela necessidade de incluir um número maior de tomadores de decisões e integrantes das equipes. Esta parece ser uma condição importante para os resultados aferidos em ambientes de negócios atuais. Além disso, a premência em estabelecer um alinhamento estratégico por parte das organizações alia-se ao desejo de fazer e encontrar sentido para os esforços cotidianos de pessoas, mobilizadas pelo valor da autoria e atitudes que os diferenciem e constituam uma identidade própria. Um anseio presente cada vez mais presente em várias dimensões da subjetividade contemporânea. 0 segundo, mais afeito à gestão, é o caráter precário e resistente à excessiva normatização, que torna a prática estratégica um investimento constante e exigente, com potencial de ganhos na medida da sua amplitude e capacidade de inovação.

Esses dois aspectos estão presentes no cotidiano de muitos estrategistas e suas equipes, independente do tamanho das organizações a que pertencem. Considerando seu aspecto exploratório, pode-se concluir que se avança um pouco na compreensão da estratégia e como ela se dá no dia a dia das organizações.

Terminam-se estas considerações, retomando uma das questões mais importantes a um estudo que se sustenta em uma abordagem ainda em formação, como a S-a-P. Ou seja, até que ponto as escolhas feitas 
e suas verificações corroboram e comprovam a visão da estratégia como uma prática? Pode-se dizer que esta investigação foi conduzida, a partir do aval dado por seus autores e pesquisadores. Ao experimentar essa sintonia entre os variados aspectos abordados pelos autores citados, em particular, arrisca-se a hipótese de que há neste estudo um potencial para discussões e troca de saberes em congressos e publicações, tanto no Brasil, quanto no mundo.

\section{Referências}

BALOGUN, J.; HUFF, A. S.; JOHNSON, P. Three Responses to the Methodological Challenges of Studying Strategizing. Journal of Management Studies, v.40, n.1. 2003.

BALOGUN, J.; JOHNSON, P. From Intended Strategies to Unintended Outcomes: The Impact of Change Recipient Sensemaking. Organization Studies OnlineFirst, 2005.

BALOGUN, J.; JOHNSON, P. Organizational restructuring and middle manager sensemaking. Organization Studies, v.26, n.11, p.573-601. 2004.

BARDIN, L. Análise de Conteúdo, Lisboa: Edições 70. 2009.

BARLEY, J. Organizational culture: can it be a source of sustained competitive advantage? Academy of Management Review, v.11, n.3, p.656-65. 1986.

BOURDIEU, P. The Logic of Practice. Cambridge, MA: Harvard University Press. 1990.

BURGI, P.; JACOBS, C.; ROOS, J. From metaphor to practice in the crafting of strategy. Journal of Management Inquiry, v.14, n.1, p.78-94. 2005.

CLEGG, S.; CARTER, C.; KORNBERGER M. A Máquina Estratégica: Fundamentos Epistemológicos e Desenvolvimentos em Curso. Revista de Administração de Empresas: v.44, n.4. 2004.

DOUGHERTY, D., BARNARD, H., DUNNE, D. Exploring the everyday dynamics of dynamic capabilities. Paper presented at the 3rd Annual MIT/UCI Knowledge and Organizations Conference, Laguna Beach, CA, March 2004.

EISENHARDT, K. Making fast strategic decisions in high-velocity environments. Academy of management Journal, v.32, n.3, p.543-76. 1989.

GIDDENS, A. A constituição da sociedade. São Paulo: Martins Fontes, 1984. 458p.
GIOIA D.; CHITTIPEDDI, K. Sense making and sense giving in strategic change initiation. Strategic Management Journal, v.12, p.433-48. 1991.

HENDRY, J.; SEIDL, D. The structure and significance of strategic episodes: social systems theory and the routine practices of strategic change. Journal of Management Studies, v.40, n.1, p.175-96. 2003.

ISI Web of Knowledge. http://apps.isiknowledge.com. 2011.

JARZABKOWSKI, P. Strategy as practice: Recursiveness, Adaptation and Practices-in-use. Organization Studies, v.25, p.259. 2004.

JARZABKOWSKI, P.; SPEE, A. P. Strategy-as-practice: A review and future directions for the field. International Journal of Management Reviews, v.11, n.1, p.69-95. 2009.

JOHNSON, G.; LANGLEY, A.; MELIN, L.; WHITTINGTON, R. Strategy as Practice: Research Directions and Resources. Cambridge: Cambridge University Press. 2007.

KING, B. L. Strategizing at leading venture capital firms: of planning, opportunism and deliberate emergence. Long Range Planning, v.41, n.3, p.345-366. 2008.

KNIGHTS, D.; MORGAN, G. Corporate strategy, organizations and subjectivity: A critique. Organization Studies, v.12, n.2, p.251-273.

LANGLEY, A. In search of rationality: the purposes behind the use of formal analysis in organizations. Unpublished PhD thesis, HEC, Montréal. 1986.

LAW, J.; CALLON, M. Engineering and sociology in a military aircraft project: a network analysis of technological change. Social Problems, v.35, n.3, p.284-97. 1988.

LEONTIEV, A. N. O desenvolvimento do psiquismo. Lisboa: Livros Horizontes, 1978.

MACIEL, C. Práxis estratégica e imersão social em uma rede de organizações religiosas. Tese de Mestrado, Universidade Federal do Paraná. 2007.

MAITLIS, S.; LAWRENCE, T. Orchestral manoeuvres in the dark: understanding failure in organizational strategizing. Journal of Management Studies, v.40, n.1, p.109-40. 2003.

MANTERE, S. Strategic Practices as Enablers and Disablers of Championing Activity. Strategic Organization. v.3, n.2, p.157-184. 
MINTZBERG, H. Patterns in Strategy Formation. Management Science, v.24, n.9, p.934-948. 1978.

MINTZBERG, H. The Nature of managerial work. New York: Harper and Row. 1973.

MINTZBERG, H.; AHLSTRAND, B.; LAMPEL, J. Safári de Estratégia: um roteiro pela selva do planejamento estratégico. Porto Alegre: Bookman. 2000.

OAKES, L.; TOWNLEY, B.; COOPER, D. Business Planning as pedagogy: language and control in a changing institutional field. Administrative Science Quarterly, v.43, n.2, p.25792. 1998.

PETTIGREW, A. Strategy formulation as a political process. International Studies of Management and Organization, v.7, n.2, p.78-87. 1977.

SAMRA-FREDERICKS, D. Strategizing as Lived Experience and Strategists' Every Day Efforts to Shape Strategic Direction. Journal of Management Studies, v.40, n.1. 2003.

SCHATZKI, T. Introduction: practice theory. In SCHATZKI et al.(2005). The sites of the social, Organization Studies, v.26, n.3, p.465-84. 2001.

VAARA, E.; WHITTINGTON, R. Strategy as Practice: Taking social practices seriously. Academy of Management Annals.

VIGOTSKY, L. S. A formação social da mente e o desenvolvimento dos processos psicológicos superiores. São Paulo:Martins Fontes, 1989.
VOLBERDA, H.W. Crise em Estratégia: Fragmentação, Integração ou Síntese. RAE, 44 (4). 2004.

WhitTington, R. Strategy as practice. Long Range Planning, v.29, n.5, p.731-735. 1996.

WHITTINGTON, R. Strategy after modernism: recovering practice. European Management Review, v.1, n.1, p.6268. 2004.

WHITTINGTON, R. Completing the practice turn in strategy. Organization Studies, v.27, n.5, p.613-34. 2006.

WILSON. D.C.; JARZABKOWISKI. P. Pensando e agindo estrategicamente: novos desafios para a análise estratégica. RAE, v.44, n.4. 2004.

YIN, R. K. Estudo de Caso: planejamento e métodos. Porto Alegre: Bookman. 2010.
Recebido: 01/08/2012

Received: 08/01/2012

Aprovado: 12/11/2012

Approved: $11 / 12 / 2012$ 